\title{
The Kessler Psychological Distress Scale (K6) as a Screening Instrument: a Study of Iranian University Students
}

\author{
Dadfar M', Lester D ${ }^{2}$, Momeni Safarabad $\mathrm{N}^{3 *}$ and \\ Roshanpajouh $\mathbf{M}^{4}$ \\ ${ }^{1}$ School of Behavioral Sciences and Mental Health-Tehran \\ Institute of Psychiatry, International Campus, School \\ of Public Health, Iran University of Medical Sciences, \\ Tehran, Iran \\ ${ }^{2}$ Psychology Program, Stockton University, Galloway, NJ , \\ USA \\ ${ }^{3}$ Lorestan University of Medical Sciences, Khoram-Abad, \\ Iran \\ ${ }^{4}$ Department of Addiction, School of Behavioral Sciences \\ and Mental Health-Tehran Institute of Psychiatry, \\ University of Medical Sciences, Iran \\ *Corresponding author: Momeni Safarabad N, \\ Lorestan University of Medical Sciences, Khoram-Abad, \\ Iran
}

Received: August 21, 2018; Accepted: October 24, 2018; Published: October 31, 2018

\section{Introduction}

The task of screening people for psychological distress has grown in importance in recent years. Suicides by university students and employees in major companies become front-page news, and institutions are increasingly considering screening all newcomers for signs of psychological distress. October 18, 2018 was the $24^{\text {th }}$ annual National Depression Screening Day in the USA. In 2017, the University of California in Los Angeles (UCLA) offered depression screening for all incoming students ${ }^{1}$. However, there are many symptoms other than depression, such as anxiety, and there may be more value in a more general screening scale.

Anxiety and mood disorders are common psychiatric disorders in the world. Major depression is a commonly occurring and burdensome disorder [1]. Kessler, Sampson, Berglund, Gruber, et al reported that patterns and correlates of comorbid DSM-IV anxiety disorders among people with DSM-IV major depression disorder (MMD) are similar across World Mental Health (WMH) countries [2]. Kessler and Bromet [3], Al-Hamzawi, Bruffaerts, Bromet, AlKhafaji and Kessler [4] indicated that major depressive episode is associated with considerable disability and low treatment in general population.

Positive psychology is concerned with the construct of psychological well-being. Two features of psychological wellbeing are a sense of control and supportive social relationships. Psychological well-being is negatively associated with psychological distress [5-6]. Psychological well-being and psychological distress can be viewed as two complementary states of mental health, and a reduction of psychological distress can improve mental health [7]. Psychological distress is a state of emotional turbulence manifested by depressive and anxiety symptoms [8], and has an impact at both cognitive and behavioral levels [9-10]. According to Stress Distress Model, psychological distress is a negative construct. This concept is influenced on physical and mental health, as well as coping with the distress [11-14].

Raza, Yousaf, and Rasheed [15] found that psychological distress was negatively associated with psychological well-being in Pakistani Muslim undergraduates and graduates, and female students had significantly higher scores on a measure of psychological distress than did males. In contrast, Kawa and Shafi [16] found that Indian male students had higher psychological distress scores than did females. Gyawali, Choulagai, Paneru, Ahmad, et al [17] reported that psychological distress symptoms correlated with demographic, behavioral, and psychosocial variables in Nepali patients with substance use disorders, and female patients reported more psychological distress than did male patients. A national mental health survey in Australia [18] found that university students reported high levels of psychological distress (9.2\% did so), and female students reported more psychological distress than did male students $(10.4 \%$ vs. $7.1 \%)$.

Psychological distress has been investigated in many studies using the Kessler Psychological Distress screening Scale (K6). The K6 is a short rating scale developed to identify persons at risk for mood disorder [19-21]. The K6, as a broader screening instrument, has advantages compared to the General Health Questionnaire-12 (GHQ-12), and the Patient Health Questionnaire-9 (PHQ-9) [17] because the $\mathrm{K} 6$ can predict mood and anxiety disorders in psychiatric patients [22-25]. The aim of the present study was to study usefulness of the K6 in predicting depression and anxiety in non-clinical samples
Ann Depress Anxiety - Volume 5 Issue 2 - 2018

ISSN : 2381-8883 | www.austinpublishing group.com

Momeni Safarabad et al. () All rights are reserved
Citation: Dadfar M, Lester D, Momeni Safarabad N and Roshanpajouh M. The Kessler Psychological Distress Scale (K6) as a Screening Instrument: a Study of Iranian University Students. Ann Depress Anxiety. 2018; 5(2): 1097. 
of university students.

\section{Materials and Methods}

\section{Subjects}

A convenience sample of 157 Iranian students was selected from Medical School at the Iran University of Medical Sciences in Tehran. Their mean age was 25.48 years $(\mathrm{SD}=8.04) ; 61.5 \%$ of them were male; $51.9 \%$ had a BA degree, $18.6 \%$ an MSc degree and $22.4 \%$ were at the basic level. They completed the Farsi versions of the Kessler Psychological Distress scale-6 (K6), and the Symptom Checklist 90 Revised (SCL-90-R) in individual sessions. The study obtained ethics approval from the Research Ethics Committee. The students completed informed consent forms. Confidentiality was assured, and student's anonymity was maintained.

\section{Measures}

The Kessler Psychological Distress Scale-6 (K6): The K6 is a shorter version of the Kessler Psychological Distress Scale-10 (K10). It measures general distress in the preceding month [26]. The K6 has two formats: an interviewer-administered format and a self-report format. The K6 has been translated for use into Arabic, Chinese, Dutch, French, Hebrew, Italian, Japanese, Nepali, Sinhalese and Spanish. The items measure whether the respondent feels nervous, hopeless, restless, jumpy, sad, and worthless. Each item of the K6 is answered on a 5-point Likert-type scale: None of the time (0); A little of the time (1); Some of the time (2); Most of the time (3), and All of the time (4). The total score ranges from 0-24 [22, 27-28]. Krynen, et al [19] indicated that the $\mathrm{K} 6 \mathrm{had}$ good psychometric properties in Pacific, Asian, Māori, and Pākehā/European peoples in New Zealand. The correlations K6 with the K10 score was $\mathrm{r}=0.89$ in college students $[23,27]$. A typical item is "During the last 30 days, about how often did you feel hopeless?"

Symptom Checklist 90 Revised (SCL-90-R): The initial form of the Symptom Checklist 90 (SCL-90) was designed by [29] to measure different psychological aspects of physical and mental illnesses. The SCL-90-R [30] has 90 items and nine subscales: Somatization (SOM), Obsessive-Compulsive (O-C), Interpersonal Sensitivity (INTS), Depression (DEP), Anxiety (ANX), Hostility (HOS), Phobic Anxiety (PHOB), Paranoid Ideation (PAR), and Psychoticism (PSY). It includes additional items from the Global Severity Index (GSI), the Positive Symptoms Distress Index (PSDI), and the Positive Symptoms Total (PST). Each item of the Checklist is rated on a four-point scale: (0) not at all, (1) little, (2) some, (3) very, (4) severe. The score for the SCL- $90-\mathrm{R}$ is calculated by dividing the total score by 90 , and ranges from 0 to 4 . Scores higher than 2 indicate psychopathology [31]. The SCL-90-R has been validated in Iran [32,33], and the Cronbachalphas ranged between 0.70 and 0.97 , and test-retest reliability 0.78 to 0.90 [34]. A typical item is "The idea that someone else can control my thoughts."

\section{Procedure}

Approval was obtained from the Research Ethics Committee before data collection began. All procedures performed in studies involving human participants were in accordance with the ethical standards of the Research Ethics Committee and with the 1964 Helsinki declaration and its later amendments or comparable ethical standards. Participants completed an informed consent form and were assured of confidentiality and anonymity. Participants first answered a demographic questionnaire, followed by the Farsi versions of the K6 and the Symptom Checklist 90 Revised (SCL-90-R) in individual sessions. Only participants with complete data were included for analysis.

\section{Statistical analyses}

All statistical analyses were performed using SPSS 23.0.

\section{Results}

The mean score on the K6 was 9.39 ( $\mathrm{SD}=5.48)$. The lowest mean item score was $1.17(\mathrm{SD}=1.31)$ for item 6 , and the highest mean item score was $1.82(\mathrm{SD}=1.21)$ for item 5 (See Table 1$)$.

The Cronbach's $\alpha$ for the K6 was 0.87 . The inter-correlations between the items ranged from 0.24 to 0.74 , and the item-total correlations ranged from 0.56 to 0.88 (See Tables $2 \& 3$ ).

The K6 correlated 0.62 with the SCL-90-R subscale of Anxiety (ANX) and 0.77 with the SCL-90-R subscale of Depression (DEP) (See Table 4).

The criteria for a factor analysis were evaluated using the KaiserMeyer- Olkin Measure of Sampling Adequacy (KMO) and Bartlett's Test of Sphericity. The KMO was 0.859 , indicating the adequacy of the sample, and Bartlett's Test of Sphericity (504.160, df $=15, \mathrm{p}<.001$ ) indicated that the factor analysis was justified. To investigate the factor structure of the scale, a Principal Component Analysis with a Varimax rotation and Kaiser Normalization were used. One component with eigenvalues greater than one was extracted labeled Psychological Distress and had an eigenvalue of 3.748, and explained $62.46 \%$ of variance (See Table 5 ).

\section{Discussion}

The K6 had good internal consistency in the present sample. A single component was identified for the K6, labeled Psychological Distress. The correlations between the K6 scores and other scale scores were high for Depression (DEP), and moderate for Anxiety (ANX). Thus, it appears that the $\mathrm{K} 6$ is appropriate for assessing depressive and anxiety symptoms in the sample, and may be a useful

Table 1: Means and SDs of the K-6 items and total score.

\begin{tabular}{|l|c|c|}
\hline \multicolumn{1}{|c|}{ (Kessler Psychological Distress Scale) Item } & Mean & SD \\
\hline Nervous & 1.68 & 1 \\
\hline Hopeless & 1.61 & 1.2 \\
\hline Restless or Fidgety & 1.63 & 1.1 \\
\hline Depression & 1.46 & 1.2 \\
\hline Everything was an effort & 1.82 & 1.2 \\
\hline Worthless & 1.17 & 1.3 \\
\hline Total score & 9.39 & 5.5 \\
\hline
\end{tabular}

Table 2: Descriptive statistics for the scales.

\begin{tabular}{|l|c|c|c|}
\hline \multicolumn{1}{|c|}{ Scales } & Mean & SD & Cronbach's $\alpha$ \\
\hline Kessler Psychological Distress Scale-6 & 9.39 & 5.48 & 0.87 \\
\hline SCL-90-R subscales & & & \\
\hline Anxiety (ANX) & 5 & 4.16 & 0.89 \\
\hline Depression (DEP) & 15.81 & 12.17 & 0.91 \\
\hline
\end{tabular}


Table 3: Inter-correlations between items and with the total score of the Kessler Psychological Distress Scale (K6).

\begin{tabular}{|c|c|c|c|c|c|c|c|}
\hline Item & $\mathbf{1}$ & $\mathbf{2}$ & $\mathbf{3}$ & $\mathbf{4}$ & $\mathbf{5}$ & $\mathbf{6}$ & Total \\
\hline $\mathbf{1}$ & 1 & & & & & & \\
\hline $\mathbf{2}$ & $\mathbf{0 . 6 1 8 ^ { * * }}$ & 1 & & & & & \\
\hline $\mathbf{3}$ & $\mathbf{0 . 6 5 0 ^ { * * }}$ & $\mathbf{0 . 7 3 6 ^ { * * }}$ & 1 & & & & \\
\hline $\mathbf{4}$ & $\mathbf{0 . 5 1 9 ^ { * * }}$ & $\mathbf{0 . 7 2 2 ^ { * * }}$ & $\mathbf{0 . 6 7 5 ^ { * * }}$ & 1 & & & \\
\hline $\mathbf{5}$ & $0.359^{* *}$ & $0.329^{* *}$ & $0.306^{* *}$ & $0.243^{* *}$ & 1 & & \\
\hline $\mathbf{6}$ & $\mathbf{0 . 5 2 8 ^ { * * }}$ & $\mathbf{0 . 7 3 1 ^ { * * }}$ & $\mathbf{0 . 5 5 6 ^ { * * }}$ & $\mathbf{0 . 6 5 5 ^ { * * }}$ & $0.358^{* *}$ & 1 & \\
\hline Total & $\mathbf{0 . 7 7 2 ^ { * * }}$ & $\mathbf{0 . 8 8 3 ^ { * * }}$ & $\mathbf{0 . 8 2 8 ^ { * * }}$ & $\mathbf{0 . 8 1 5 ^ { * * }}$ & $\mathbf{0 . 5 6 0 ^ { * * }}$ & $\mathbf{0 . 8 2 8 ^ { * * }}$ & 1 \\
\hline
\end{tabular}

Table 4: Pearson correlations ( $r$ ) between the scale scores.

\begin{tabular}{|l|c|}
\hline \multicolumn{1}{|c|}{ Scale } & $r$ with the $\mathrm{K6}$ \\
\hline SCL-90-R subscales & \\
\hline Anxiety (ANX) & $0.621^{* *}$ \\
\hline Depression (DEP) & $0.775^{* *}$ \\
\hline
\end{tabular}

Table 5: Factor loadings (>0.5) of the Kessler Psychological Distress Scale (K6) in Iranian college students.

\begin{tabular}{|l|c|}
\hline \multicolumn{1}{|c|}{ Kessler Psychological Distress Scale (K6) Items } & Component \\
\cline { 2 - 2 } & $\mathbf{1}$ \\
\hline $\begin{array}{l}\text { 1. During the last } 30 \text { days, about how often did you feel nervous? } \\
\text { 2. During the last } 30 \text { days, about how often did you feel } \\
\text { hopeless? }\end{array}$ & $\mathbf{0 . 7 8 2}$ \\
\hline $\begin{array}{l}\text { 3. During the last } 30 \text { days, about how often did you feel restless } \\
\text { or fidgety? }\end{array}$ & $\mathbf{0 . 8 5}$ \\
\hline $\begin{array}{l}\text { 4. During the last } 30 \text { days, about how often did you feel so sad } \\
\text { that nothing could cheer you up? }\end{array}$ & $\mathbf{0 . 8 3 2}$ \\
\hline $\begin{array}{l}\text { 5. During the last } 30 \text { days, about how often did you feel that } \\
\text { everything was an effort? }\end{array}$ & 0.486 \\
\hline $\begin{array}{l}\text { 6. During the last } 30 \text { days, about how often did you feel } \\
\text { worthless? }\end{array}$ & $\mathbf{0 . 8 2 3}$ \\
\hline Eigen value & 3.748 \\
\hline \% of Variance & 62.46 \\
\hline
\end{tabular}

tool for evaluating psychological distress in research and in nonclinical settings.

The results replicate those of earlier research by others. Gyawali, et al. [17] found a Cronbach's $\alpha$ of 0.89 in addicted patients, while Dadfar, et al. [22] found a Cronbach's $\alpha$ of 0.88 , test-retest reliability 0.80 , and item-total correlations ranging from 0.50 to 0.92 , with one factor (64.57\% of variance) labeled: Psychological Distress in Iranian psychiatric outpatients. Easton, Safadi, Wang and Hasson [35] reported that scores on the Arabic version of K6 correlated 0.66 with Generalized Anxiety Disorder (GAD-7) and 0.61 with the Somatic Symptoms Scale (SSS-8), indicating good convergent validity. Kang, et al. [36] found that the K6 had good reliability and validity in Chinese undergraduate students: the test-retest reliability was 0.79 ; Cronbach's a 0.84 ; sensitivity 0.83 ; specificity 0.79 ; positive predictive value 0.60 ; and negative predictive value 0.80 . Cornelius, Groothoff, van der Klink, et al [37] showed that the K6 was a reliable and valid scale for screening for DSM-IV psychiatric disorders. The optimal cut-off score was 14, and the positive predictive value and the negative predictive values for the optimal cut point of the K6 of 0.51 and 0.87 . They indicated that the K6 can be used as a guide for a follow-up clinical interview in order to diagnose psychiatric disorders. Arnaud, Malet, Teissedre, Izaute, et al. [38] reported that threshold scores were 10 for the K6 (sensitivity: 0.92; specificity: 0.62), Cronbach's a 0.76 , correlations 0.83 with the Hospital Anxiety and Depression Scale (HADS) scores and 0.51 with the Hamilton Depression Rating Scale (HDRS) scores in patients with alcohol-related disorders. There have been reports of factor analyses with two factors [35, 39-40], and a single factor [41-44]. Green, Gruber, Sampson, Zaslavsky, et al. [43] found that there is a need to add of indexes of behavior disorders to the K6 to screen sufficiently for serious emotional disturbance in American adolescents.

\section{Conclusion}

The present study indicates that the K6 is a reliable and useful instrument for screening non-clinical populations and may be easily included in applications by potential students and workers applying for positions. The study was carried out in Iranian university students, and so the generalizability of the results to other populations merits more investigation. It is hoped that the study will stimulate further cross-cultural research on the K6, will be useful in future population mental health surveys, and will prove for the identification of subclinical cases.

\section{Conflict of Interest}

There were no competing interests, and no financial support for the study.

\section{Acknowledgement}

The authors thank all subjects for their participation. The study was no supported by a financial grant.

Foot Nate: ${ }^{1}$ https://khn.org/news/ucla-offers-depressionscreening-to-thousands-of-incoming-students/

\section{References}

1. Kessler RC. The costs of depression. Psychiatric Clinics of North America. 2012; 35: 1-14.

2. Kessler RC, Sampson NA, Berglund P, Gruber MJ, Al-Hamzawi A, Andrade $\mathrm{L}$, et al. Anxious and non-anxious major depressive disorder in the World Health Organization World' Mental Health Surveys. Epidemiology and Psychiatry Sciences. 2015; 24: 210-226.

3. Kessler RC, Bromet EJ. The epidemiology of depression across cultures. Annual Review of Public Health. 2013; 34: 119-138.

4. Al-Hamzawi AO, Bruffaerts R, Bromet EJ, AlKhafaji AM, Kessler RC. The epidemiology of major depressive episode in the Iraqi general population. PLoS One. 2015; 10: e0131937.

5. Ruini C. Positive psychology in the clinical domains: Research and practice Springer International Publishing. 2017.

6. Winefield RH, Gill KT, Taylor WA, Pilkington MA. Psychological well-being and psychological distress: is it necessary to measure both? Psychology of Well-Being: Theory, Research and Practice. 2012; 2: 1-14.

7. Vilas Boas AA, Morin EM. Psychological well-being and psychological distress for professors in Brazil and Canada. Revista de Administração Mackenzie. 2014; 15: 201-219.

8. Mirowsky J, Ross CE. Measurement for a human science. Journal of Health and Social Behavior. 2002; 43: 152-170.

9. Yasien S, Abdul Nasir J, Shaheen T. Relationship between psychological distress and resilience in rescue workers. Saudi Medical Journal. 2016; 37 778-782.

10. Ahmad S, Arshad T, Kausar R. Psychological correlates of distress in rescue 
1122 workers in Pakistan. International Journal of Emergency Mental Health and Human Resilience. 2015; 17: 486-494

11. Gust DA, Gvetadze R, Furtado M, Makanga M, Akelo V, Ondenge K, et al. Factors associated with psychological distress among young women in Kisumu, Kenya. International Journal of Women's Health. 2017; 2: 255-264.

12. Habelrih EA, Hicks RE. Psychological well-being and its relationships with active and passive procrastination. International Journal of Psychological Studies. 2015; 7: 25-34.

13. Horwitz AV. Distinguishing distress from disorder as psychological outcomes of stressful social arrangements. Health. 2007; 11: 273-289.

14. Ridner SH. Psychological distress: concept analysis. Journal of Advanced Nursing. 2004; 45: 536-545.

15. Raza H, Yousaf A, Rasheed R. Religiosity in relation with psychological distress and mental wellbeing among Muslims. International Journal of Research Studies in Psychology. 2016; 5: 65-74.

16. Kawa MH, Shafi $\mathrm{H}$. Evaluation of internet addiction and psychological distress among university students. International Journal of Modern Social Sciences. 2015; 4: 29-41.

17. Gyawali B, Choulagai BP, Paneru DP, Ahmad M, Leppin A, Kallestrup P. Prevalence and correlates of psychological distress symptoms among patients with substance use disorders in drug rehabilitation centers in urban Nepal: a cross-sectional study. BMC Psychiatry. 2016; 16: 314

18. Furukawa TA, Kessler RC, Slade T, Andrews G. The performance of the K6 and K10 screening scales for psychological distress in the Australian National Survey of Mental Health and Well-Being. Psychological Medicine. 2003; 33 357-362.

19. Krynen AM, Osborne D, Duck IM, Carla A, Houkamau CA, Sibley AG. Measuring psychological distress in New Zealand: item response properties and demographic differences in the Kessler-6 screening measure. New Zealand Journal of Psychology. 2013; 42: 95-109.

20. Andersen LS, Grimsrud A, Myer L, Williams DR, Stein DJ, Seedat S. The psychometric properties of the $\mathrm{K} 10$ and $\mathrm{K} 6$ scales in screening for mood and anxiety disorders in the South African Stress and Health study. International Journal of Methods in Psychiatric Research. 2011; 20: 215-223.

21. Baggaley RF, Ganaba R, Filippi V, Kere M, Marshall T, Sombié I, et al. Detecting depression after pregnancy: the validity of the K10 and K6 in Burkina Faso. Tropical Medicine \& International Health. 2007; 12: 1225-1229.

22. Dadfar M, AtefVahid MK, Lester D, Bahrami F. Kessler Psychological Distress Scale (K6): Psychometric testing of the Farsi form in psychiatric outpatients. Advances in Bioresearch. 2016; 7: 105-108.

23. AtefVahid MK, Dadfar M, Kessler RC, Bahrami F, Lester D. Validation of Fars version of the Kessler Psychological Distress Scale (K10) in college students. European Journal of Social Science. 2015; 49: 115-124.

24. Kessler RC, Barker PR, Colpe LJ, Epstein JF, Gfroerer JC, Hiripi E, et al. Screening for serious mental illness in the general population. Archives of General Psychiatry. 2003; 60: 184-189.

25. Kessler RC, Green JG, Gruber MJ, Sampson NA, Bromet E, Cuitan M, et al. Screening for serious mental illness in the general population with the K6 screening scale: Results from the WHO World Mental Health (WMH) survey initiative. International Journal of Methods in Psychiatric Research. 2010; 19 4-22.

26. Kessler RC, Andrews G, Colpe LJ, Hiripi E, Mroczek D, Normand S-LT, et al. Short screening scales to monitor population prevalences and trends in nonspecific psychological distress. Psychological Medicine. 2002; 32: 959-976.

27. Dadfar M, Lester D, AtefVahid MK, Nasr Esfahani M. The psychometric parameters of the Farsi form of the Kessler Psychological Distress Scale (K10) in psychiatric outpatients. International Journal of Medical Research \& Health Sciences. 2016; 5: 1-7.
28. Suraweera CH, Hanwella R, Sivayokan S, Varuni de Silva V. Rating Scales validated for Sri Lankan populations. Sri Lanka Journal of Psychiatry. 2013; 4: $16-24$

29. Derogatis LR, Lipman RS, Covi L. SCL-90: an outpatient psychiatric rating scale-preliminary report. Psychopharmacology Bulletin. 1973; 9: 13-28.

30. Derogatis LR. SCL-90-R: administration, scoring of procedures manual-II for the $r$ (revised) version and other instruments of the psychopathology rating scale series. $2^{\text {nd }}$ Edition, Clinical Psychometric Research, Inc., Towson. 1992.

31. Sereda Y, Dembitskyi S. Validity assessment of the symptom checklist SCL90-R and shortened versions for the general population in Ukraine. BMC Psychiatry. 2016; 16: 300

32. Ardakani A, Seghatoleslam T, Habil H, Jameei F, Rashid R, Zahirodin A et al. Construct validity of Symptom Checklist-90-Revised (SCL-90-R) and General Health Questionnaire-28 (GHQ-28) in patients with drug addiction and diabetes, and normal population. Iranian Journal of Public Health. 2016; 45: 451-459.

33. Anisi J, Akbari F, Majdian M, Atashkar M, Ghorbani. Standardization of mental disorders Symptoms Checklist 90 Revised (SCL-90 -R) in army staffs. Journal of Military Psychology. 2011; 2: 29-37.

34. Zakiei A, RajabiGilan N, Reshadat S, Ghasemi SR. The role of socia trust in explaining psychological disorders in Kermanshah, Iran. Journal of Mazandaran University Medical Sciences. 2015; 25: 119-127.

35. Easton SD, Safadi NS, Wang Y, Hasson III, RG. The Kessler psychological distress scale: translation and validation of an Arabic version. Health Quality of Life Outcome. 2017; 15: 215.

36. Kang YK, Guo WJ, Xu H, Chen YH, Li XJ, Tan ZP, et al. The 6-item Kessler psychological distress scale to survey serious mental illness among Chinese undergraduates: Psychometric properties and prevalence estimate. Comprehensive Psychiatry. 2015; 63: 105-112.

37. Cornelius BLR, Groothoff JW, van der Klink JJ, Brouwer S. The performance of the K10, K6 and GHQ-12 to screen for present state DSM-IV disorders among disability claimants. BMC Public Health. 2013; 13: 128.

38. Arnaud B, Malet L, Teissedre F, Izaute M, Moustafa F, Geneste J, et al Validity study of Kessler's Psychological Distress Scales conducted among patients admitted to French emergency department for alcohol consumptionrelated disorders. Alcoholism, Clinical and Experimental Research. 2010; 34: 1235-1245

39. Lace JW, Merz ZC, Grant AF, Emmert NA, Zane KL, Handal PJ. Validation of the $\mathrm{K} 6$ and its depression and anxiety subscales for detecting nonspecific psychological distress and need for treatment. Current Psychology. 2018.

40. Bessaha ML. Factor structure of the Kessler Psychological Distress Scale (K6) among emerging adults. Research on Social Work Practice. 2017; 27: 616-624

41. Ko J, Harrington D. Factor structure and validity of the $\mathrm{K} 6$ scale for adults with suicidal ideation. Journal of the Society for Social Work and Research. 2016; 7: 43-63.

42. Mewton L, Kessler RC, Slade T, Hobbs MJ, Brownhill L, Birrell L, et al. The psychometric properties of the Kessler Psychological Distress Scale (K6) in a general population sample of adolescents. Psychological Assessment. 2016; 28: $1232-1242$.

43. Green JG, Gruber MJ, Sampson NA, Zaslavsky AM, Kessler RC. Improving the $\mathrm{K} 6$ short scale to predict serious emotional disturbance in adolescents in the USA. International Journal of Methods in Psychiatric Research. 2010; 19: 23-35.

44. Kessler RC. The costs of depression. Psychiatric Clinics of North America. 2012; 35: 1-14.
Ann Depress Anxiety - Volume 5 Issue 2 - 2018

ISSN : 2381-8883 | www.austinpublishinggroup.co

Momeni Safarabad et al. (C) All rights are reserved
Citation: Dadfar M, Lester D, Momeni Safarabad N and Roshanpajouh M. The Kessler Psychological Distress Scale (K6) as a Screening Instrument: a Study of Iranian University Students. Ann Depress Anxiety. 2018; 5(2): 1097. 